accommodation. They must not be so handicapped in the more pressing times to come. The Council of the Royal Society has appointed a committee to consider the needs for fundamental researches in physics; no doubt other departments of science will have similar needs. The primary duty of the Royal Society is to aid researches which seek the advancement of knowledge without immediate reference to its use, though it appreciates clearly that such progress is often necessary to practical advances. Finally, Sir Henry referred to the need of the Royal Society for a home more worthy of its importance; he spoke of investigations which have been made, with the help of the assistant secretary, Mr. Griffith Davies, of the different homes the Society has occupied. Elsewhere in this issue (p. 649) we print Sir Henry's remarks on this topic.

\section{Scientific Work in India}

Is the August number of Discovery, Sir Lewis Fermor gives an interesting account of the history and development of pure and applied science in India. It is well known that India possesses a very ancient culture and civilization. As regards ancient science, the Hindus made important contributions to mathematics, and, as Sir Lewis points out, they possessed a considerable knowledge of zoology, medicine and chemistry. Sir Prafulla Chandra Ray's book on the "History of Hindu Chemistry" from the earliest times up to the middle of the sixteenth century A.D. provides valuable information concerning this branch of science. The conquests of Alexander the Great gave India an important stimulus to intercourse with Europe, but, as Sir Lewis observes, much ancient Indian science antedates this Greek influence. Moreover, it must not be forgotten that when the Arabs brought science to Europe, their knowledge derived from Indian as well as Greek sources. Although in its earlier days the East India Company did not employ scientific men as such in India, it is a striking fact that James Prinsep, one of the Company's official assayers, deciphered in 1838 the ancient Brahmi script used in the rock-cut inscriptions or edicts of the Indian Buddhist king, Asoka (died circa 237 B.c.).

According to Sir Lewis Fermor, the modern development and study of science in India began with the coming in 1783 of the Puisne Judge of the Supreme Court, Sir William Jones, who in 1784 founded the "Asiatick Society", later to become the Royal Asiatic Society of Bengal. A portrait of Sir William Jones accompanies the article. Concerning the very great development of Government services depending on applied science, universities and colleges, scientific societies, scientific journals, and academies of science, which has taken place in India during the nineteenth and especially the twentieth century, readers will find here an excellent account. The universities, colleges, and academies of modern India, including the Indian Institute of Science at Bangalore, founded by the eminent Parsee family of Tata, make import. ant contributions to the advance of pure and applied science. A number of these discoveries are referred to by Sir Lewis, who adorns his article with the photographs of eight eminent Indian men of science, namely, Dr. H. J. Bhabha, Sir Shanti Swarupa Bhatnagar, Dr. K. S. Krishnan, Sir C. Venkata Raman, Prof. M. N. Saha, Prof. B. Sahni, the late Sir J. Chandra Bose (all fellows of the Royal Suciety), and Sir P. Chandra Rry.

\section{Insulin Colour Code}

NotewORTHY steps in the direction of co-operation in production and distribution have been made by the four firms (Allen and Hanburys Ltd., Boots Pure Drug Co. Ltd., British Drug Houses Ltd., and Burroughs Wellcome and Co.) entrusted with the manufacture of insulin in Great Britain. These' firms, mindful of their special responsibilities to the diabetic community, have throughout the War period pooled their research, manufacturing and distributive facilities to ensure an adequate and uninterrupted supply of their products to those in daily need of them and to reduce their prices, in the face of rising material and labour costs, to the lowest practicable level. Three distinct types of insulin-Unmodified Insulin, Protamine Zinc Insulin and Globin Insulin (with Zinc)-are in regular use in Great Britain. Alternative strengths of two of these make a total of six different preparations, and confusion between them might easily be attended by serious consequences. To reduce this possibility to a minimum, the British insulin manufacturers have agreed to adopt a uniform design for labels and cartons, by which each type and strength of insulin, of whatever make, will be readily identifiable by a distinctive colour scheme. In addition, the unit strength per c.c. will be displayed in bold figures on both label and carton. An explanatory card, printed in colours, is obtainable from any of the manufacturers on request. The change, which will take place on January 1 , was made after consultation with leading authorities and with the approval of the Ministry of Health.

\section{Animal Population of a Seaport}

Av exhibit entitled "The Population of a Seaport" was recently installed in the Zoology Department of the National Museum of Wales. It is based on the fact that any great city to-day is a habitat characterized by a particular community of animal species; in this case including, and largely dependent on, man. Examples of this urban fauna-certain birds, domestic animals, rodent and insect pests, etc.-are shown; and the interrelationships of the species, between themselves and with man, illustrated by coloured tapes running from one animal to another and thence to a small bust representing man. As man created the habitat for this community, he can control it for the better, notably by improved town-planning, whereby, for example, desirable bird-life may ke in. creased, and improved house-building, whereby rats, cockroaches, etc., may be diminished. As indicated in the labels, these and some other urban pests were originally introduced by shipping, and specimens are displayed of the numerous alien species that thus reach our seaports; those which have established themselves, however, have mostly spread inland and are to-day familiar in all large towns. As about 80 per cent of the population of Britain are urban dwellers, such an exhibit should assist the majority of visitors to envisage this biological background to their environment, and the advantages to be achieved by its improvement and control. An article describing the exhibit appears in the October number of the Journal of the Royal Institute of British Architects.

\section{Recording Cathode Ray Oscillograph Traces}

The technique of recording cathode ray oscillo. graph traces was the subject chosen for the November meeting of the Association for Scientific Photography, the speakers being Mr. W. Nethercot (E.R.A.) and 